robotic arm that sits atop a moving box.

Cooper estimates that mobile robots cost $£ 30,000-120,000$ to build. The hardware in his factory is configured to make multicomponent catalyst formulations that involve both solids and liquids, but a different set-up would be needed to do multistep organic synthesis, he says. The robot is built to handle solids, with up to 100 cartridges of solid compounds to choose from.

At the moment, the robot has no real user interface and requires a programmer to instruct it. But once that is up and running, Burger says, "any lab technician could be trained on this in a matter of weeks".

The goal is not to create a mindless worker bee, Cooper says. The robot has an algorithm that will instantaneously determine its next step or action, on the basis of an iterative process that relates chemical composition to the catalytic activity, thus allowing the prediction of material compositions that are better than any studied so far. This, he says, is very different from how a human would approach the problem. "It's selection, it's not design."

The system has already discovered competitive photocatalysts, he notes, and can even handle solids, a key ingredient in the development of catalysts. Analysing solids, dispensing them and using them in tiny channels is a huge technological challenge, Cooper says. But he notes that his robot is already capable of dispensing solids, and his team is working on automating analytical techniques, such as powder X-ray diffraction, to determine the molecular structure of the compounds.

Researchers who hope to test-drive chemistry automation can also look to Imperial's Centre for Rapid Online Analysis of Reactions, which was officially opened in January. The facility, which cost more than $£ 4.5$ million, includes two commercially available continuous-flow reactors, a host of analytical equipment and a suite of robotic reactor platforms.

Ben Partridge, an organic chemist at the University of Sheffield, UK, has booked time at the centre. Automation, he says, allows more data to be gathered in less time, and with greater accuracy. "You can get more information from fewer chemical reactions. Ultimately, it will also give students more time to think and be creative, as they do not need to spend as many hours at the bench."

And that's true for students and professionals alike. Automation, says Seeberger, "empowers the chemist". In 2015, when Burke reported his synthesis machine, some chemists debated whether automation would spell the end for synthetic chemistry. For Burke, the opposite is true. "It doesn't mean synthesis is no longer important," he says. "It means we get to aim higher." -

Katharine Sanderson is a science writer based in Foix, France.

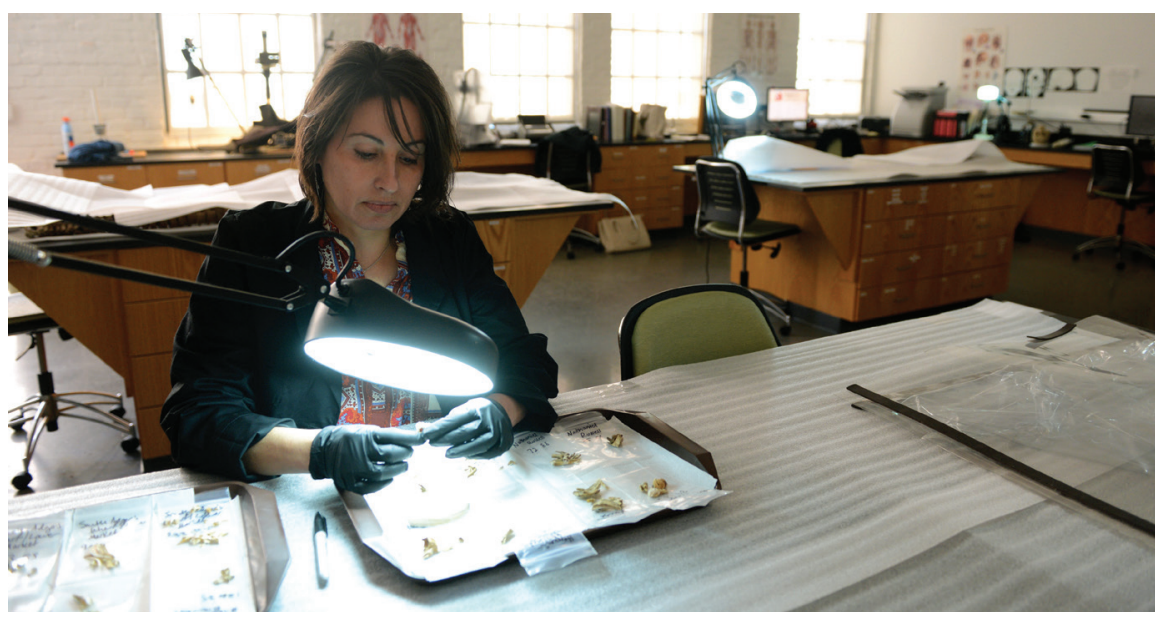

Forensic anthropologist Ann Ross identifying bone fragments in her laboratory.

\title{
Bone of contention
}

\section{Forensic anthropologist Ann Ross finds artificial intelligence tools wanting.}

\section{BY JEFFREY M. PERKEL}

I n the late 1990s, as an anthropology $\mathrm{PhD}$ student at the University of Tennessee, Knoxville, Ann Ross travelled to Bosnia to help identify casualties of war. In her current role as head of the Human Identification and Forensic Analysis Laboratory at North Carolina State University in Raleigh, she does much the same for the people of her state. Her lab - a refurbished engineering space measuring about 90 square metres - has a contract with the North Carolina Office of the Chief Medical Examiner, which means that when a human skeleton is recovered, it is her job to determine what happened. The lab has enough tables for four skeletons. Most days, Ross says, all the tables are occupied: her lab is revisiting each of the state's 130 -odd cold cases, many dating back decades, to see whether modern forensic science can shed light on what happened.

"Our methods have changed so much that they really need a fresh set of eyes," Ross says. The modern techniques she can deploy on old bones include stable isotope analysis to assess an individual's place of birth, and radiocarbon dating to determine year of birth.

Ross also has methods of her own design. One, a software package called 3D-ID, uses measurements of craniofacial landmarks and a database of 2,372 individuals to estimate ethnicity. Another helps to estimate age at death - a crucial metric when trying to assign a name to unknown remains.

Conventionally, Ross says, age estimates are made visually, based on 'wear and tear' of the bones. But wear and tear isn't necessarily a reliable indicator, because it can be influenced by socio-economic factors, such as diet and occupation. So some forensic anthropologists are making estimates on the basis of bonemineral density (BMD) instead.

BMD depends mostly on age, Ross notes. BMD readings rise until about the age of 20 , plateau, and then fall in adulthood, regardless of diet and activity. That makes BMD, which is measured using a standard hospital scanner, a more reliable metric than visual confirmation, Ross says. But the exact relationship with age remains unclear.

In 2018, researchers in Portugal released an online tool called DXAGE that uses artificial intelligence and BMD data on 100 Portuguese and southern European women aged 21-95 to estimate age at death (D. Navega et al. J. Forensic Sci. 63, 497-503; 2018). Working with researchers at the University of South Florida in Tampa and a collection of some 470 samples, Ross put DXAGE to the test, and found it wanting. Although the software performed well for individuals aged 30-39, estimates for other age ranges were off by between 5 and 23 years (J. D. Bethard et al. J. Forensic Sci. http://doi. org/c4mq; 2018).

In her own work, Ross favours a simple linear-regression model to extrapolate age. Although it can also be prone to errors, it's easier to explain to a jury, she says. In research, the consequence of a faulty algorithm is wasted time. But in a court of law, lives are on the line. "If you go into court, and the judge asks you, 'Hey, so how did you develop this?' And you're like, 'I don't know, the machine did it, that's really not a good answer." - 